Journal of Applied Pharmaceutical Science Vol. 6 (10), pp. 037-044, October, 2016

Available online at http://www.japsonline.com

DOI: $10.7324 / \mathrm{JAPS} .2016 .601005$

ISSN 2231-3354 (cc) BY-NC-SA

\title{
Physical stabilization of amorphous itraconazole in solid dispersions for improved dissolution profile
}

\author{
Yogesh Vilas Pore, Vikram Ramchandra Shinde*, J. Venkateswara Rao \\ Government College of Pharmacy, Karad, Maharashtra, India 415 124., Bharat School of Pharmacy, Mangalpally (V), Ibrahimpatanam (M), R. R. Dist, \\ Hyderabad, India.
}

\begin{tabular}{|c|c|}
\hline ARTICLE INFO & ABSTRACT \\
\hline Article history: & \multirow{11}{*}{$\begin{array}{l}\text { The main objective of the present investigation was to improve dissolution efficiency and stabilize amorphous } \\
\text { form of itraconazole (ITR) through formulation of ternary solid dispersion system (SDs) with } \\
\text { polyvinylpyrrolidone K30 (PVP K30) and sylysia }{ }^{\circledR} 350 \text { using spray drying technique. The prepared ternary SD } \\
\text { system was characterized for solid state properties, in vitro dissolution efficiency and accelerated stability study } \\
\text { at } 40{ }^{\circ} \mathrm{C} / 75 \% \text { RH for the period of } 3 \text { months to explore extent of stabilization of amorphous itraconazole } \\
\text { (AITR). Surprisingly, AITR was found to have no significant improvement in its dissolution characteristics } \\
\text { compared to pure drug. The formation of cohesive supercooled liquid state might be the reason for poor } \\
\text { solubility. Hence a combined approach of SD system with an antiplasticizing agent and surface adsorption } \\
\text { technique was employed to prevail over functional inabilities of AITR. The binary and ternary SDs of AITR } \\
\text { were prepared employing PVP K30 as antiplasticizer and/or sylysia }{ }^{\circledR} 350 \text { as adsorbent in the ratio } 1: 1: 1 \mathrm{w} / \mathrm{w} \\
\text { using spray drying technique. The prepared systems have shown significant improvement in dissolution } \\
\text { characteristics when compared to pure drug. Accelerated stability studies confirmed the absence of } \\
\text { crystallization events over a period of } 3 \text { months endorsing excellent stabilization of AITR. }\end{array}$} \\
\hline $4 / 03 / 2016$ & \\
\hline $\operatorname{Re}$ & \\
\hline & \\
\hline Available & \\
\hline Key words: & \\
\hline Itraconazole; amorphous; & \\
\hline solid dispersion; physical & \\
\hline stability; dissolution. & \\
\hline & \\
\hline & \\
\hline
\end{tabular}

\section{INTRODUCTION}

Crystallinity of an active pharmaceutical ingredient (API) offers potential benefit in ease of formulation design and contributes to thermodynamic stability (Paul et al., 2011; Byrn et al., 1999; Brittain, 1999) . However, some APIs exist in different crystalline phases and thus exhibit polymorphism which can adversely influence solubility and dissolution rate leading to poor oral bioavailability and reduced therapeutic efficacy (Llinas and Goodman, 2008; Yadav et al., 2009). Superior physicochemical properties and improved therapeutic performance of such drugs can be realized by crystalline to amorphous state transformation (Craig et al., 1999; Lian, 2001; Pokharkar et al., 2006). Different preparative techniques to achieve the modified solid state have

\footnotetext{
* Corresponding Author

Vikram Ramchandra Shinde, Government College of Pharmacy, Karad, Maharashtra,India.Email: shinde_vicky26 @ rediffmail.com
}

been reported so far were quench cooling, milling, spray drying etc. It is beneficial of using amorphous form of a poorly water soluble drug instead of its crystalline form as former represents high energy state and hence provides benefits including enhanced solubility, higher rate of dissolution and improved bioavailability (Hancock and Zografi, 1997). However, key limitations associated with the amorphous phase need to be addressed are poor thermodynamic stability and higher chemical reactivity which may be attributed to stress favored devitrification during manufacturing operations and/or storage (Pokharkar et al., 2006). Further, water vapor, a plasticizer, plays an important role in adversely affecting physico-chemical properties of amorphous solids (Jondhale et al., 2012). Thus, to fully exploit solubility advantages of amorphous drugs, there is a definite need to stabilize them in solid state. Among various alternatives toward enhancing the stability of an amorphous pharmaceutical solid, formulation of a solid dispersion with a glass former (antiplasticizer) having high glass transition temperature $(\mathrm{Tg})$ seems promising one (Saleki-Gerhardt and Zografi, 1994; Shamblin et al., 1996). 
From investigations reported so far, it appears that water soluble biocompatible carriers, namely, polyvinylpyrrolidone K30 (PVP K30), hydroxypropyl methylcellulose and polyethylene glycol usually exert their antiplasticizing effect and can stabilize amorphous phase by elevating $T \mathrm{~g}$. Further, porous hydrophilic silica (sylysia ${ }^{\circledR} 350$ ) can be employed as a third component to supplement their antiplasticizing effect.

Itraconazole (ITR), a synthetic triazole, widely adopted as an antifungal agent, inhibits cytochrome P-450 14- $\alpha$ desmethylase dependent synthesis of ergosterol, which is a vital component of fungal cell membranes (Lewis, 2011). ITR, classified as a BCS class II drug, has poor solubility in aqueous media (less than $0.001 \mathrm{mg} \mathrm{mL}^{-1}$ at $25^{\circ} \mathrm{C}$ ) (Shete et al., 2015) and has a dissolution rate limited poor oral bioavailability with $\mathrm{pKa}$ of 3.7 (Heykants et al., 1989) with due consideration of its relatively low $T$.

Some investigations have reported formulation of solid dispersion systems (SDs) of crystalline ITR (CITR) (Jung et al., 1999; Verreck et al., 2003; Wang et al., 2005; Tao et al., 2009). However, till date, very less attention is paid towards preparing and stabilizing amorphous form of ITR (AITR) employing ternary SDs for improvement of its solubility. Therefore, the main objective of the present investigation was to improve dissolution efficiency and stabilize AITR through formulation of ternary SDs with PVP K30 and/or sylysia ${ }^{\circledR} 350$ using spray drying technique.

\section{MATERIALS AND METHODS}

\section{Materials}

Itraconazole was a gift sample from Glenmark Pharma (Mumbai, India). PVP K30 and sylysia ${ }^{\circledR} 350$ were generously supplied by Signet Chem. Lab. Mumbai, India and Fuji Sylysia Chemical Ltd., Japan respectively. All reagents used were of analytical grade. Double distilled water was used throughout the experiment.

\section{Preparation of an amorphous state}

Melt quench cooling technique was employed for preparation of amorphous state of ITR. Melting of ITR crystals in a steel container under controlled conditions of temperature was followed by quench cooling of the melt in an intimate freezing mixture (mixture of an ice and sodium chloride) for about 1-1.5 h. The solidified material was then stored in desiccators until further investigation.

\section{Thin layer chromatography}

Thin-layer chromatography (TLC) was used to notice any possibility of degradation of the drug during preparation of amorphous phase. Silica gel $\mathrm{G}$ and a mixture of chloroform: benzene (40:10) was employed as a stationary and a mobile phase respectively. For visualization of the spots plate was kept for few minutes in a closed container having atmosphere saturated with iodine vapor. Behavior of the drug on the TLC was described by calculating and checking relative mobility or $\mathrm{R}_{f}$ value at every instance.

\section{Preparation of binary and ternary amorphous solid dispersions (SDs)}

Spray drying technique was used to prepare SDs of AITR. AITR alone, AITR with either PVP K30 or sylysia ${ }^{\circledR} 350$ $(1: 1 \mathrm{w} / \mathrm{w})$ and AITR with PVP K30 and sylysia ${ }^{\circledR} 350(1: 1: 1 \mathrm{w} / \mathrm{w})$ were dissolved in sufficient amount of chloroform with the formation of clear solutions. The solutions were then spray dried using laboratory scale spray dryer (Labultima, LU 222 advanced, Mumbai, India) under the following set of conditions: inlet temperature $60{ }^{\circ} \mathrm{C}$, outlet temperature $45^{\circ} \mathrm{C}$, cool temperature 35 ${ }^{\circ} \mathrm{C}$, feed rate $8-10 \mathrm{ml} / \mathrm{min}$; atomization air pressure $2 \mathrm{~kg} / \mathrm{cm}^{2}$ and aspiration rate $60 \mathrm{mBar}$. The formulations were coded as shown in table 1 and stored in desiccator till further analysis is carried out.

Table 1: Codes for all systems.

\begin{tabular}{ll}
\hline Batch Code & Description of system \\
\hline CITR & Pure crystalline itraconazole \\
AITR & Spray dried amorphous itraconazole \\
F1 & Binary dispersion with PVP K30 \\
F2 & Binary dispersion with sylysia ${ }^{\circledR} 350$ \\
F3 & Ternary dispersion with PVP K30 and sylysia ${ }^{\circledR} 350$ \\
\hline
\end{tabular}

\section{Determination of drug content}

SDs equivalent to $10 \mathrm{mg}$ were dissolved in $10 \mathrm{ml}$ of methanol and volume was suitably adjusted to $100 \mathrm{ml}$ with distilled water. Then samples were filtered using a $0.45-\mu \mathrm{m}$ filter and spectrophotometric analysis for drug content was carried out at $\lambda$ max $262 \mathrm{~nm}$ using UV-Visible spectrophotometer (Shimadzu1800, Japan). Experiments were run in triplicate and data are presented as mean values.

\section{Fourier transformation infrared spectroscopy (FTIR)}

FTIR spectra of pure CITR, PVP K30, sylysia ${ }^{\circledR} 350$ and all binary and ternary SDs were obtained using a Jasco V550 Japan, spectrophotometer. Samples were thoroughly blended with dry potassium bromide and compressed into disks. $10 \mathrm{mg}$ amount of each sample was scanned through the wave range of 4,000-400 $\mathrm{cm}^{-1}$.

\section{Differential scanning calorimetry (DSC)}

Thermal analysis was carried out employing TA SDT 2960 DSC (USA) differential scanning calorimeter. 3 - $5 \mathrm{mg}$ amount of each sample was sealed in an aluminum pan while an empty aluminum pan was utilized as a reference. The sample was heated in the range of 30 to $200{ }^{\circ} \mathrm{C}$ with an underlying heating rate of $10{ }^{\circ} \mathrm{C} / \mathrm{min}$. Dry nitrogen at flow rate of $40 \mathrm{ml} / \mathrm{min}$ was used to cleanse DSC cell.

\section{X-ray powder diffractometry (XRPD)}

The XRPD diffraction study was performed with Philips Analytic X-Ray - PW 1729 (Philips, Almelo, The Netherlands) with a copper tube anode. 3 to $5 \mathrm{mg}$ of sample of each formulation 
was analyzed between the interval $5-50^{\circ} 2 \theta$ with scanning speed of $2 \%$ min. The diffraction pattern was measured with generator tension (voltage) and generator current of $40 \mathrm{kV}$ and $30 \mathrm{~mA}$ respectively.

\section{Dissolution studies}

Dissolution experiments for all binary and ternary SDs were carried out using Disso 2000, LabIndia, India apparatus and according to USP II method (paddle method). For simulation of dissolution of the ITR in stomach, simulated gastric fluid (SGF) without enzyme maintained at $37 \pm 0.5{ }^{\circ} \mathrm{C}$ was used as a dissolution medium at rotation speed of $100 \mathrm{rpm}$. An amount of formulation equivalent to $100 \mathrm{mg}$ of ITR dose was added to the dissolution medium. Sampling was carried out at 10, 20, 30, 45, 60 and 90 min recommended time intervals and the sink condition was maintained by immediate replacement with an equal volume of fresh dissolution medium each time. Samples were then filtered through $0.45 \mu \mathrm{m}$ membrane filter and diluted suitably. Finally, spectrophotometric analysis was carried out at $\lambda \max 262 \mathrm{~nm}$ with UV-visible spectrophotometer (Shimadzu-1800, Japan). All studies were carried out in triplicate.

\section{Stability studies}

Accelerated stability testing for all SDs was conducted for 3 months at $40 \pm 2{ }^{\circ} \mathrm{C}$ and $75 \pm 5 \% \mathrm{RH}$ in accordance with the guidelines developed by International Conference on Harmonization ( $\mathrm{ICH})$. Aluminum capped glass vials containing known amount of samples were kept in environmental test chamber (Modern Industrial Corporation, INDIA) for the recommended period. Samples were taken out periodically after 0 , 1 and 3 months and characterized by XRPD and DSC studies. Further, dissolution studies of the same samples were carried out.

\section{Statistical analysis}

The results were expressed as the mean standard deviation and statistical analysis was carried out using appropriate method wherever necessary.

\section{RESULTS AND DISCUSSION}

\section{Thin-layer chromatography}

TLC studies were performed to identify any degradation of ITR during melting. $\mathrm{R}_{f}$ values for both crystalline and amorphous form were found at around 0.82 each time. Identical $\mathrm{R}_{f}$ values and absence of any additional spot in the amorphous state run confirmed stability of the drug during melting process.

\section{Fourier transformation infrared spectroscopy (FTIR)}

The IR spectrum of CITR (Figure $1 \mathrm{~A}$ ) is characterized by principle peaks at $3142 \mathrm{~cm}^{-1}$ (C-H aromatic); $2995 \mathrm{~cm}^{-1}(\mathrm{C}-\mathrm{H}$ aliphatic); $1725 \mathrm{~cm}^{-1}(\mathrm{C}=\mathrm{O}$, amide carbonyl $) ; 1400 \mathrm{~cm}^{-1}(\mathrm{C}=\mathrm{N})$; $1480 \mathrm{~cm}^{-1} \quad\left(\mathrm{C}=\mathrm{C}\right.$ aromatic); $1237 \mathrm{~cm}^{-1}$ (C-N, ring stretch, heterocyclic); $1030 \mathrm{~cm}^{-1}(\mathrm{C}-\mathrm{O}-\mathrm{C})$ and $1080 \mathrm{~cm}^{-1}(\mathrm{C}-\mathrm{Cl})$. Very little difference in overall spectrum with slight shift in few characteristic peaks was observed in case of AITR (Figure 1 D). In the spectra for the binary SDs of amorphous drug with PVP K30 (Figure $1 \mathrm{E}$ ) and with sylysia ${ }^{\circledR} 350$ (Figure $1 \mathrm{~F}$ ), the absorption bands of ITR assigned to $\mathrm{C}$ - $\mathrm{H}$ aliphatic stretch and $\mathrm{C}=\mathrm{O}$ amide carbonyl stretch were shifted towards lower intensity and get broadened. Further, presence of broad peak at $3495 \mathrm{~cm}^{-1}$ might be attributed to hydrogen bonding between drug and PVP K30 (Mulye et al., 2012; Kumar et al., 2011).

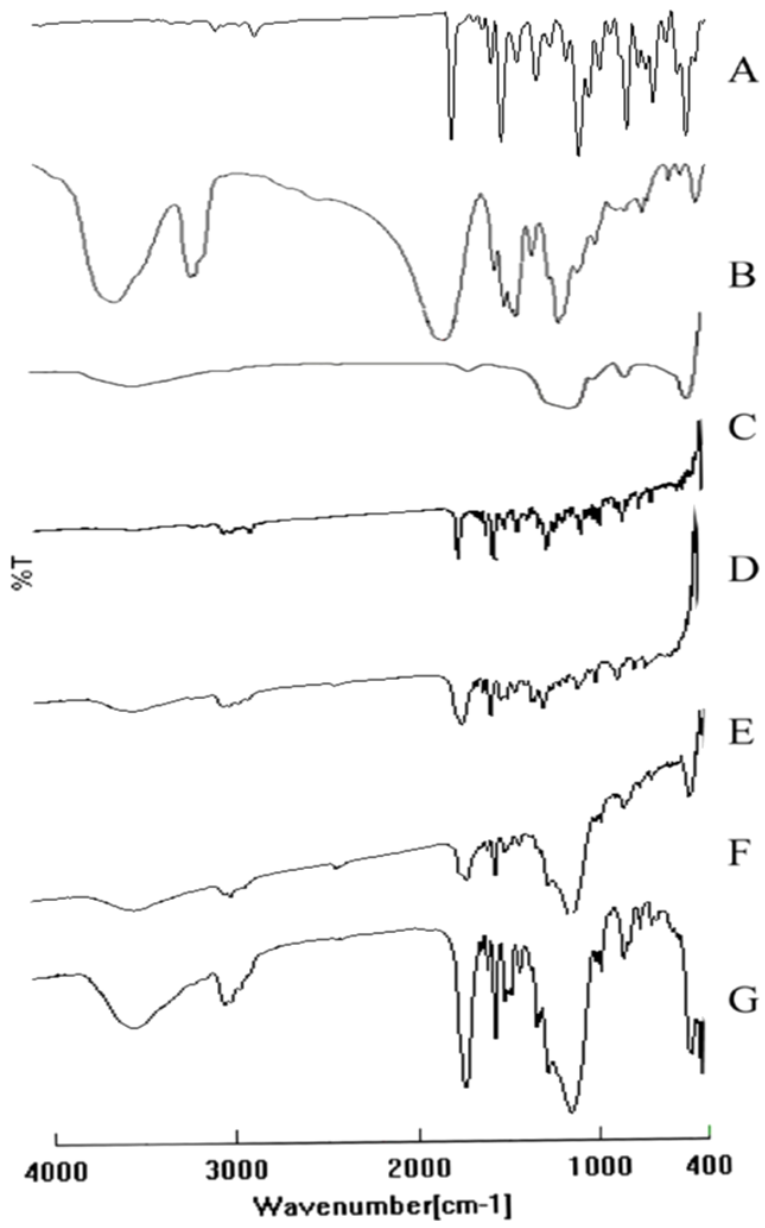

Fig. 1: FTIR spectra of all systems. (A) CITR, (B) PVP K30, (C) sylysia ${ }^{\circledR} 350$, (D) AITR, (E) F1, (F) F2 and (G) F3. CITR: crystalline itraconazole; PVPK30: polyvinylpyrrolidone K30; AITR: amorphous Itraconazole.

In ternary solid dispersion system (Figure $1 \mathrm{G}$ ), peaks corresponding to $\mathrm{C}-\mathrm{H}$ aliphatic and $\mathrm{C}-\mathrm{H}$ aromatic stretch were not visible, indicating strong hydrogen bonding between silanol groups of ternary component i.e. sylysia ${ }^{\circledR} 350$ and functional groups of ITR (Sammour et al., 2006). Furthermore, all other peaks corresponding to ITR spectrum were present with reduced peak intensities and were smoothened, which might be a cause of strong physical interaction between drug and polymer. However, all binary and ternary SDs showed no any additional peaks in their spectrum, indicating absence of any type of chemical interaction between drug and carriers including ternary component (Ford, 1986). 


\section{Differential scanning calorimetry (DSC)}

DSC thermograms of CITR, AITR and its amorphous dispersions are shown in Figure 2. DSC thermogram of CITR (Figure $2 \mathrm{~A}$ ) depicted sharp endothermic peak at $170{ }^{\circ} \mathrm{C}$ owing to its melting which specified its crystalline nature. The DSC thermogram of AITR (Figure $2 \mathrm{~B}$ ) showed a glass transition onset peak at $61{ }^{\circ} \mathrm{C}$ followed by recrystallization exotherm at $113{ }^{\circ} \mathrm{C}$ and an endothermic peak at $165^{\circ} \mathrm{C}$. Sequential happening of glass transition and recrystallization events might be attributed to crystallization of glassy state (Ambike et al., 2004).

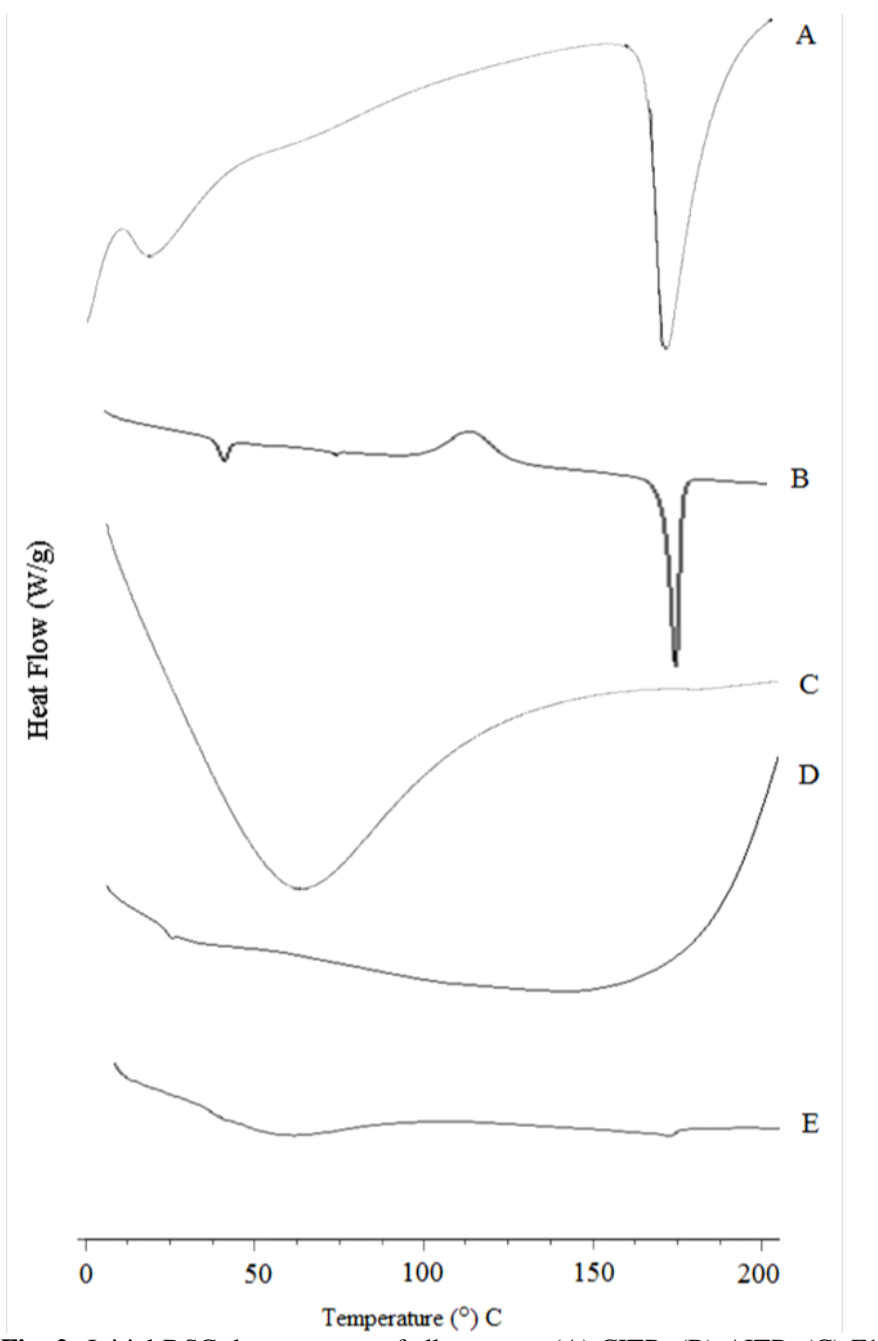

Fig. 2: Initial DSC thermograms of all systems. (A) CITR, (B) AITR, (C) F1, (D) F2 and (E) F3. CITR: crystalline itraconazole; AITR: amorphous itraconazole.

The thermogram of spray dried binary SDs of amorphous drug with PVP K30 (Figure 2 C) exhibited a broad endotherm at about $71{ }^{\circ} \mathrm{C}$ as a result of loss of water and was devoid of corresponding endothermic peak of ITR suggesting formation of amorphous state.

Further, DSC thermograms of binary SD system of the amorphous drug with sylysia ${ }^{\circledR} 350$ (Figure 2 D) and ternary SD system with PVP K30 and sylysia ${ }^{\circledR} 350$ (Figure 2 E) were devoid of melting endotherm of ITR. The complete disappearance of endothermic transition of ITR in both binary and ternary SD systems gives clear evidence of transformation of the drug from crystalline to amorphous state. The results were also supported by XRPD studies (Figure 3 C-E). It could be observed that, PVP K30 has inhibited recrystallization of AITR by its antiplasticizing effect. This effect has been augmented by sylysia ${ }^{\circledR} 350$ in ternary solid dispersions.

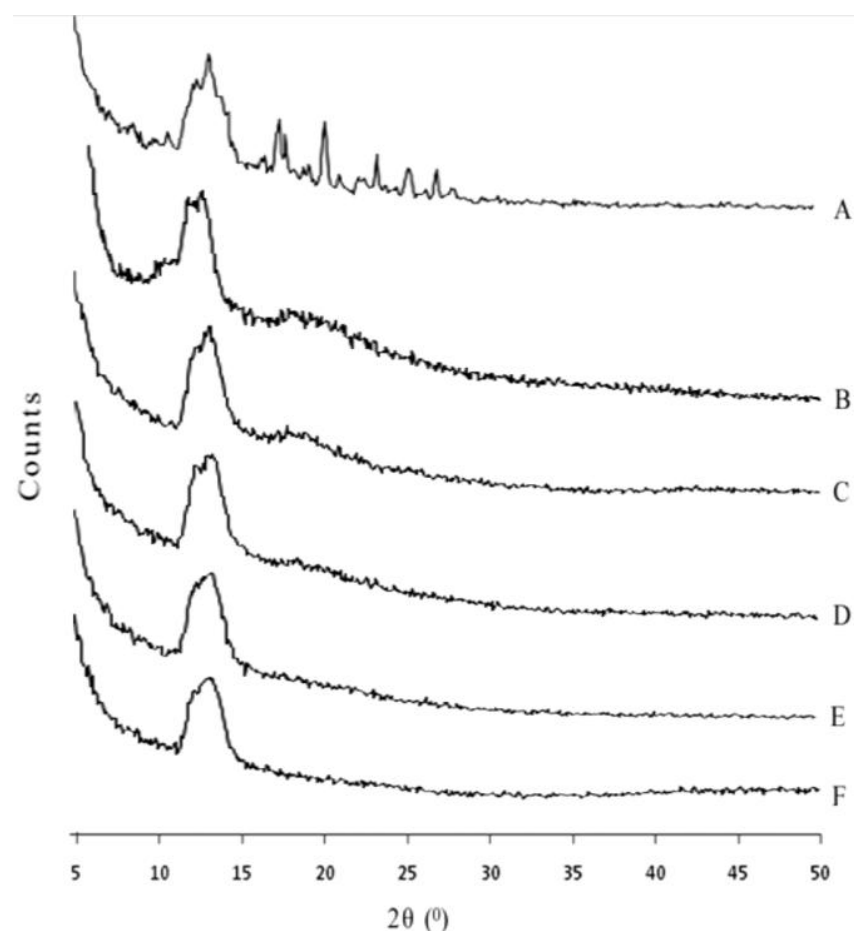

Fig. 3: Initial XRPD spectra of all systems. (A) CITR, (B) PVP K30, (C) AITR, (D) F1 (E) F2 and (F) F3. CITR: crystalline itraconazole; PVPK30: polyvinylpyrrolidone K30; AITR: amorphous itraconazole.

\section{X-ray powder diffractometry (XRPD)}

Figure 3 depicts XRPD patterns for CITR, AITR and its spray dried dispersions. XRPD pattern for CITR (Figure $3 \mathrm{~A}$ ) showed sharp intense peaks at $13.3^{\circ}, 18^{\circ}$ and $20.4^{\circ}(2 \theta)$ with peak intensities 934, 473 and 543 counts respectively demonstrating its crystalline nature.

XRPD pattern of AITR (Figure $3 \mathrm{C}$ ) demonstrated a hollow pattern corresponding to its amorphous nature as confirmed by its thermal analysis (Figure 2 B). Almost all intense peaks attributing to ITR had completely disappeared in XRPD spectra of binary and ternary SD systems (Figure 3 D - F). Furthermore, presence of hollow pattern and absence of any diffraction peaks in the spectra of these dispersion systems might be attributed to transformation of ITR from crystalline to its amorphous state. These results were also supported by absence of melting endotherm and presence of $\mathrm{Tg}$ characteristic to glassy transition state in DSC thermograms of the dispersions. 


\section{Drug content}

Percentage drug content of all formulations was found to be in the range of $82.52 \pm 1.93 \%$ to $96.46 \pm 1.8 \%(n=3$ for each formulation).

\section{Dissolution studies}

The dissolution curves of CITR, AITR and its SDs in SGF without enzyme at $37 \pm 0.5^{\circ} \mathrm{C}$ are shown in Figure 4. It was evident that all formulations have significantly improved dissolution profile of ITR as compared to CITR and AITR systems $(p<0.001)$. The basis for evaluation of dissolution data as shown in table 2 was \% drug dissolved at $5 \mathrm{~min}\left(\mathrm{DP}_{5}\right), 15 \mathrm{~min}\left(\mathrm{DP}_{15}\right)$ and dissolution efficiency at $15 \mathrm{~min}\left(\mathrm{DE}_{15}\right)$.

Table 2: The dissolution data of CITR, AITR and its various binary and ternary systems with PVP K30 and/or sylysia ${ }^{\circledR} 350$ in simulated gastric fluid (SGF) without enzyme at $37 \pm 0.5^{\circ} \mathrm{C}$ at initial.

\begin{tabular}{llll}
\hline \multicolumn{1}{c}{ System } & DP $_{\mathbf{5}}{ }^{*}$ & \multicolumn{1}{c}{$\mathbf{D P}_{\mathbf{1 5}}{ }^{*}$} & \multicolumn{1}{c}{ DE $_{\mathbf{1 5}}{ }^{{ }^{*}}$} \\
\hline CITR & $2.41 \pm 1.7$ & $4.45 \pm 1.5$ & $2.91 \pm 0.67$ \\
AITR & $10.43 \pm 2.8$ & $10.33 \pm 3.9$ & $5.78 \pm 2.5^{\mathrm{a}}$ \\
F1 & $20.36 \pm 2.3$ & $22.24 \pm 2.7$ & $10.80 \pm 3.4^{\mathrm{a}}$ \\
F2 & $43.10 \pm 3.4$ & $45.86 \pm 4.8$ & $23.74 \pm 2.7^{\mathrm{b}}$ \\
F3 & $63.52 \pm 4.1$ & $62.49 \pm 4.2$ & $32.96 \pm 3.1^{\mathrm{b}}$ \\
\hline
\end{tabular}

CITR: crystalline itraconazole; AITR: amorphous itraconazole; ${ }^{*}$ Mean \pm S.D. $(n=3)$; S.D.: Standard deviation; $\mathrm{DP}_{5}$ : $\%$ Drug dissolved at $5 \mathrm{~min}$; $\mathrm{DP}_{15}: \%$ Drug dissolved at $15 \mathrm{~min} ; \mathrm{DE}_{15}$ : Dissolution efficiency at $15 \mathrm{~min}$; ${ }^{\mathrm{a}}$ no significant difference compared to CITR $(p>0.05) ;{ }^{\text {b }}$ significant difference compared to CITR and AITR $(p<0.001)$.

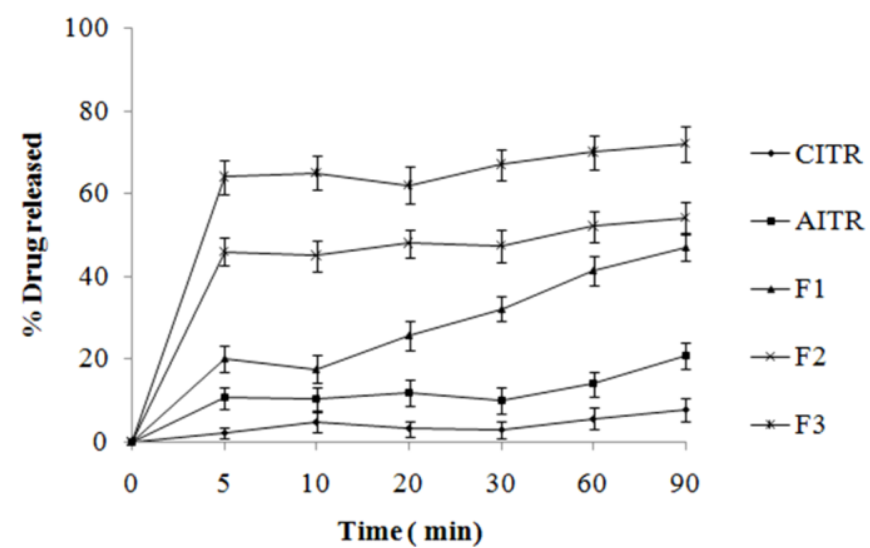

Fig. 4: Initial dissolution profile of all systems including pure drug in simulated gastric fluid (SGF) without enzyme at $37 \pm 0.5^{\circ} \mathrm{C}$.

CITR: crystalline itraconazole; AITR: amorphous itraconazole.

CITR showed only $7.71 \pm 1.26 \%$ drug release within 90 min in the dissolution medium. However, no significant difference $(p>0.05)$ was observed between release rates of ITR from AITR system and binary system prepared with PVP K30 (F1) compared with CITR. This may be caused by an attainment of equilibrium state leading to conversion of an amorphous drug into a cohesive supercooled liquid state close to glass transition temperature. Further, agglomeration and strong adhesion of individual particles of amorphous form of ITR might lead to poor dissolution profile.

In case of binary system prepared with sylysia ${ }^{\circledR} 350$ (F2), significantly improved $\left(\mathrm{DE}_{15} 23.74 \pm 2.7 \%, p<0.001\right)$ dissolution profile over pure drug was observed. This could be due to reduced crystallinity and presence of amorphous form of ITR as confirmed by DSC and XRPD studies. Further, hydrophilic nature of the carrier which improves wettability of the system and increased surface area by spray drying could be significantly contributed for improved rate and extent of dissolution of ITR.

In ternary dispersion system (F3), sylysia ${ }^{\circledR} 350$ was used as a ternary component which is porous in nature. Hydrophilic nature of silicon dioxide particles could be one of the major reasons along with above mentioned reasons for the improvement of dissolution rate of ITR. Fine silica particles with large specific surface area have silanol groups on their surfaces which can absorb drug molecules through hydrogen bond formation. This interaction imparts good dispersibility of drug molecules into the carrier system and further improves wettability. Furthermore, amorphous state assumed by adsorbed drug molecules led to improved dissolution.

\section{Stability studies}

It is well documented that, upon storage, high temperature and humidity seem to induce recrystallization of amorphous drugs formulated in SDs (Ambike et al., 2004). Hence, in order to evaluate performance of AITR upon storage, accelerated stability studies were performed up to 3 months as per ICH guidelines $\left(40{ }^{\circ} \mathrm{C} / 75 \% \mathrm{RH}\right.$ ) (Nair et al., 2002). Results of initial characterization described above, indicated that SDs were more beneficial as compared to AITR and hence all were subjected to accelerated stability testing.

Thermal analysis of samples subjected to accelerated stability studies for 1 and 3 months is illustrated in Figure 5. The DSC curve of AITR (Figure $5 \mathrm{~A}$ ) upon aging for 1 month showed a broad recrystallization exotherm at around $113{ }^{\circ} \mathrm{C}$ followed by an intensified melting endotherm at $165{ }^{\circ} \mathrm{C}$ indicating devitrification of AITR and incidence of recrystallization. After 3 months, more pronounced effect of devitrification has been observed for AITR, where melting endotherm at $165^{\circ} \mathrm{C}$ was more intensified (Figure $5 \mathrm{E}$ ). The transition of glassy state to crystalline form via supercooled liquid state might owe to absorption of moisture by AITR during aging (Ambike et al., 2004).

Spray dried binary SD system of the amorphous drug with PVP K30 aged for 1 month (Figure $5 \mathrm{~B}$ ) showed presence of broad endotherm in the range of $72.5-97.7{ }^{\circ} \mathrm{C}$ associated with $\mathrm{Tg}$ which could be attributable to enthalpy recovery and structural relaxation of amorphous form towards the supercooled liquid region (Ambike et al., 2004). Further, presence of weak intensified melting endotherm at $165{ }^{\circ} \mathrm{C}$ indicated partial devitrification of amorphous ITR and incidence of crystallinity (Figure $5 \mathrm{~B}$ ). Binary system of ATIR with PVPK30, upon aging for 3 months, experienced more prominent structural relaxation and increased rate of devitrification as well as increased incidence of crystallinity attributed to greatly intensified endotherm at $163.37{ }^{\circ} \mathrm{C}$ (Figure 5 F). This is indicative of functional inability of AITR from stability point of view. 
Spray dried binary SD system of the amorphous drug with sylysia ${ }^{\circledR} 350$ aged for 1 month (Figure 5 C) did not show thermodynamic transition corresponding to the melting of drug. This might owe to masking of the melting transition by sylysia ${ }^{\circledR} 350$. However, on aging after a period of 3 months, binary system incorporated with sylysia ${ }^{\circledR} 350$, experienced relaxation endotherm associated with $T \mathrm{~g}$ indicating partial devitrification and transformation of an amorphous to crystalline state of the drug (Figure $5 \mathrm{G}$ ).

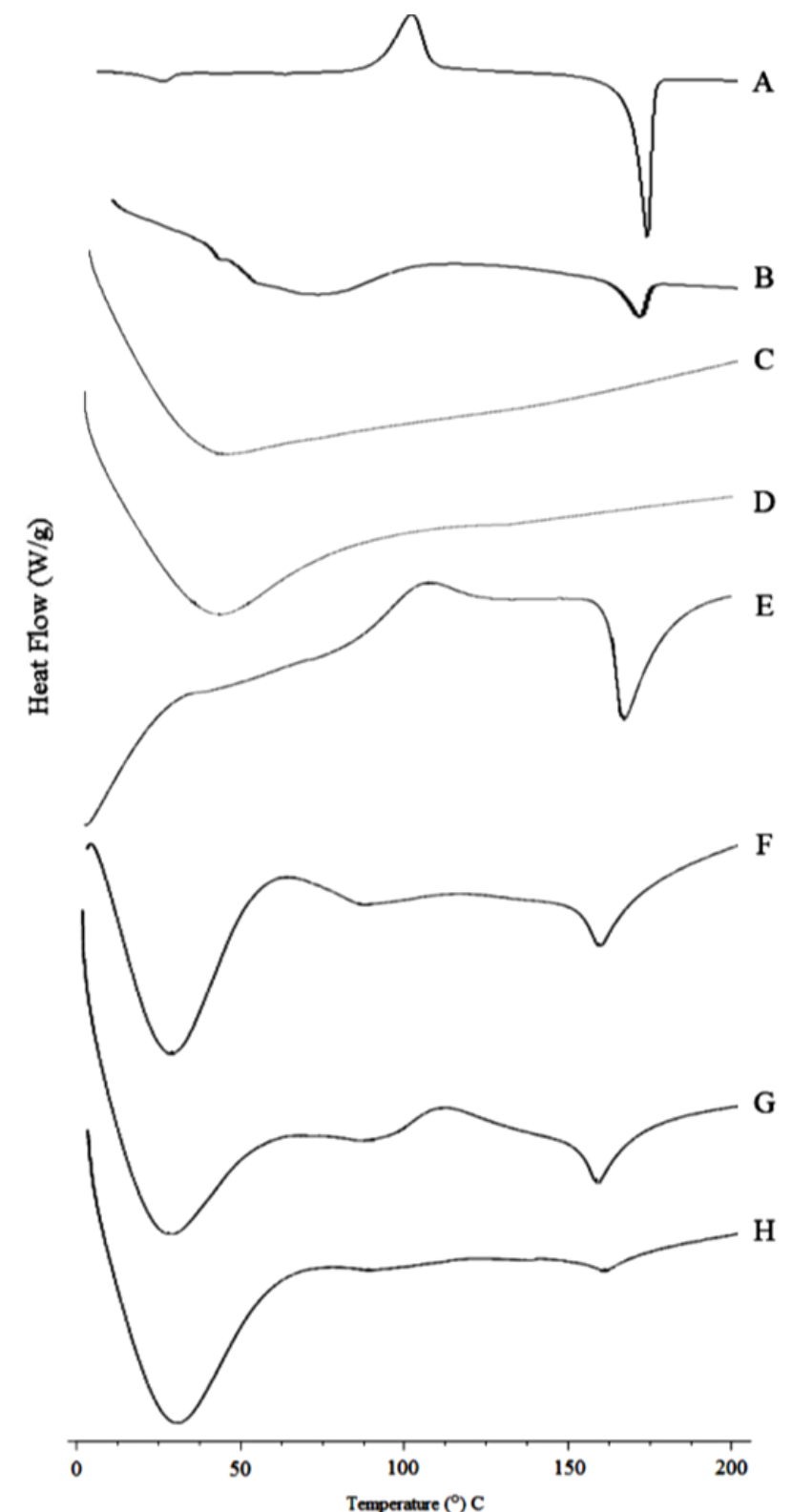

Fig. 5. DSC thermograms during stability studies (1 and 3 months). (A-D) DSC thermograms after 1 month. (E - H) DSC thermograms after 3 months. (A) AITR, (B) F1, (C) F2, (D) F3, (E) AITR, (F) F1, (G) F2 and (H) F3.

AITR: amorphous itraconazole.

Upon aging for 1 and 3 months, the thermograms of ternary dispersion of AITR with PVP K30 and sylysia ${ }^{\circledR} 350$ produced neither melting transition associated with $T \mathrm{~g}$ nor any crystallinity incidence (Figure $5 \mathrm{D} \& 5 \mathrm{H}$ ). This is indicative of excellent stabilization of amorphous state of ITR in spray dried ternary systems of sylysia ${ }^{\circledR} 350$ among all formulation. Thus, the improved stability of amorphous form of ITR in spray-dried ternary SDs might be because of antiplasticizing property of PVP K30 which was further augmented by the presence of an adsorbent (sylysia $\left.{ }^{\circledR} 350\right)$ which protected the system from moisture. The XRPD spectra, after 1 and 3 months, for all the systems subjected for accelerated stability study $\left(40^{\circ} \mathrm{C} / 75 \% \mathrm{RH}\right)$ are shown in Figure 6.

After 1 month, the AITR showed peaks at $13.2^{\circ}, 19.9^{\circ}$, $21.1^{\circ} \& 22.6^{\circ}(2 \theta)$ values. Prominent but less intense peaks as compared to the crystalline form were observed (Figure $6 \mathrm{~A}$ ). After 3 months, XRPD spectra of AITR showed some prominent diffraction peaks with higher intensities clearly suggesting deteriorated \& devitrified state of the drug (Figure 6 E). The results were supported by presence of melting endotherm in DSC study.

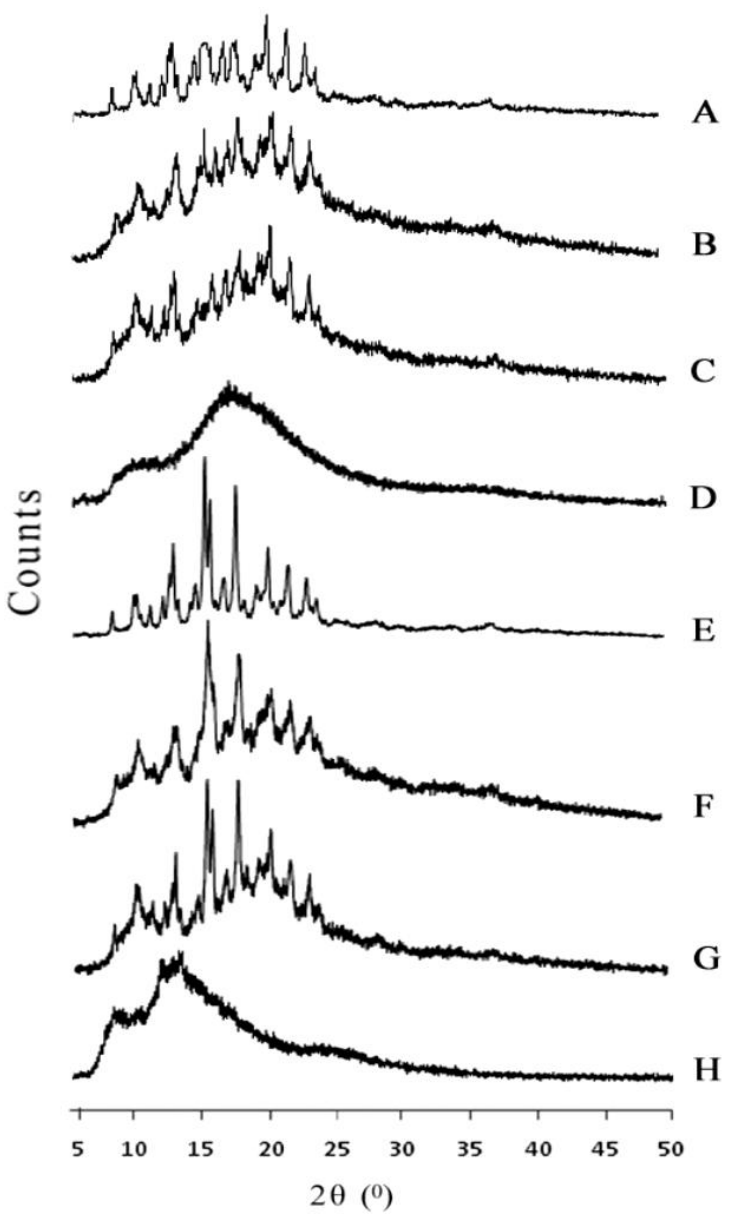

Fig. 6. XRPD spectra during stability studies (1 and 3 months). (A-D) XRPD spectra after 1 month. (E - H) XRPD spectra after 3 months. (A) AITR, (B) F1, (C) F2, (D) F3, (E) AITR, (F) F1, (G) F2 and (H) F3.

AITR: amorphous itraconazole.

Binary SD system prepared with PVP K30, after $1 \& 3$ months of aging, showed some incidences of crystallinity with characteristic ITR peaks (Figure $6 \mathrm{~B}, \mathrm{~F}$ ). This finding is in accordance with the DSC study which showed small endotherm 
corresponding to melting of the drug. After 1 \& 3 months, binary SD system prepared with sylysia ${ }^{\circledR} 350$ showed some incidences of slight crystallinity. Although, no incidence of melting endotherm has been observed in its DSC study, advocating very low rate of devitrification, system failed to protect amorphous state of the drug (Figure $6 \mathrm{C}, \mathrm{G})$.

The spray dried ternary system with PVP K30 and sylysia $^{\circledR} 350$, after 1 month, showed absence of any diffraction peaks indicating existence of amorphous form of the drug (Figure 6 D). For the system, a characteristic halo diffraction pattern corresponding to an amorphous nature was observed even after 3 months (Figure $6 \mathrm{H}$ ). The thermogram of ternary system showing nonexistence of melting endotherm of the drug obtained in DSC analysis supports these results. This obviously suggests that combined use of PVP K30 and sylysia ${ }^{\circledR} 350$ as an antiplastisizer (Pokharkar et al., 2006) and an adsorbent respectively, augmented each other's effect and proved to be a successful strategy to stabilize the amorphous state of ITR for long run.

Dissolution profiles of samples in SGF without enzyme maintained at $37 \pm 0.5^{\circ} \mathrm{C}$, subjected to accelerated stability studies for 1 and 3 months, are depicted in Figure 7 . The \% drug dissolved at $5 \mathrm{~min}\left(\mathrm{DP}_{5}\right), 15 \mathrm{~min}\left(\mathrm{DP}_{15}\right)$ and dissolution efficiency at $15 \mathrm{~min}$ $\left(\mathrm{DE}_{15}\right)$ values of the pure amorphous drug and all formulations are shown in Table 3 and 4.

Table 3 The Dissolution data of AITR and its SD systems after 1 month in simulated gastric fluid (SGF) without enzyme at $37 \pm 0.5^{\circ} \mathrm{C}$.

\begin{tabular}{llll}
\multicolumn{1}{c}{ System } & \multicolumn{1}{c}{ DP $_{5}{ }^{*}$} & \multicolumn{1}{c}{ DP $_{15}{ }^{*}$} & \multicolumn{1}{c}{ DE $_{15}{ }^{*}$} \\
\hline AITR & $8.57 \pm 1.9$ & $9.79 \pm 3.6$ & $4.69 \pm 2.3$ \\
F1 & $20.46 \pm 1.7$ & $21.28 \pm 3.2$ & $11.54 \pm 2.8$ \\
F2 & $30.75 \pm 3.8$ & $38.72 \pm 3.5$ & $19.57 \pm 4.8^{\text {a }}$ \\
F3 & $59.92 \pm 5.4$ & $62.38 \pm 4.7$ & $31.49 \pm 3.7^{\text {a }}$ \\
\hline
\end{tabular}

AITR: amorphous itraconazole; ${ }^{*}$ Mean \pm S.D. $(n=3)$; S.D.: Standard deviation; $\mathrm{DP}_{5}$ : \% Drug dissolved at $5 \mathrm{~min} ; \mathrm{DP}_{15}$ : \% Drug dissolved at $15 \mathrm{~min}$; $\mathrm{DE}_{15}$ : Dissolution efficiency at $15 \mathrm{~min} ;{ }^{\mathrm{a}}$ significant difference compared to AITR $(p<0.001)$.

Table 4 The Dissolution data of AITR and its SD systems after 3 months in simulated gastric fluid (SGF) without enzyme at $37 \pm 0.5^{\circ} \mathrm{C}$.

\begin{tabular}{llll}
\hline System & DP $_{5}{ }^{*}$ & DP $_{15}{ }^{*}$ & DE $_{15}{ }^{*}$ \\
\hline AITR & $7.26 \pm 3.4$ & $11.87 \pm 2.7$ & $5.64 \pm 3.3$ \\
F1 & $20.76 \pm 2.8$ & $20.95 \pm 3.6$ & $10.91 \pm 4.3$ \\
F2 & $21.24 \pm 4.2$ & $39.52 \pm 5.3$ & $18.82 \pm 3.6^{\mathrm{a}}$ \\
F3 & $54.65 \pm 4.4$ & $59.69 \pm 4.7$ & $29.48 \pm 3.4^{\mathrm{a}, \mathrm{b}}$ \\
\hline
\end{tabular}

AITR: amorphous itraconazole; " Mean \pm S.D. $(n=3)$; S.D.: Standard deviation; $\mathrm{DP}_{5}$ : \% Drug dissolved at $5 \mathrm{~min} ; \mathrm{DP}_{15}$ : \% Drug dissolved at $15 \mathrm{~min}$; $\mathrm{DE}_{15}$ : Dissolution efficiency at $15 \mathrm{~min} ;{ }^{\text {a }}$ significant difference compared to AITR $(p<0.001) ;{ }^{\text {b }}$ significant difference compared to AITR, F1 and F2 $(p<0.05)$.

All formulations showed significantly better dissolution profile when compared statistically with amorphous state $(p<0.001)$. Statistical analysis has shown slight decrease (non significant) in dissolution of itraconazole from AITR formulation after 1 and 3 months. Devitrification of glassy material occurred during accelerated stability studies might have contributed to this (Ambike et al., 2004). This could also be endorsed by results obtained from DSC and XRPD studies. Binary systems prepared with PVP K30 or sylysia ${ }^{\circledR} 350$ (F1 and F2) failed to improve dissolution profile during accelerated stability study (Figure 7).
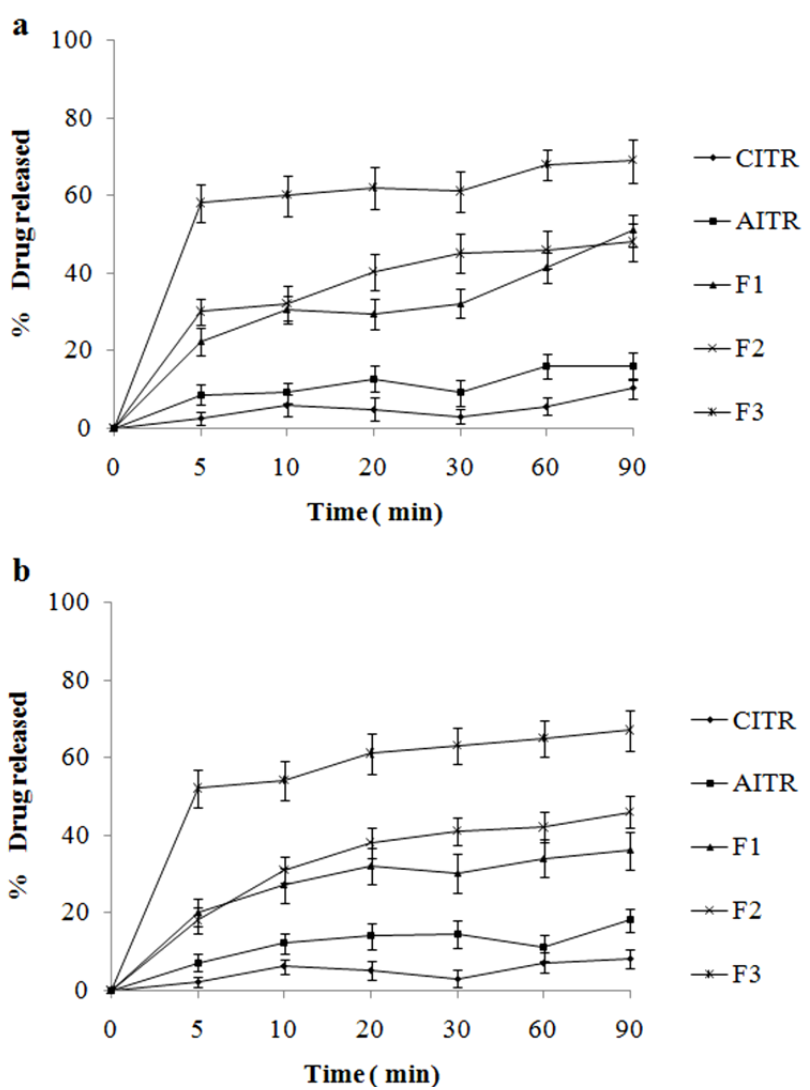

Fig. 7:

a. Dissolution profile of all systems after 1 month in simulated gastric fluid (SGF) without enzyme at $37 \pm 0.5{ }^{\circ} \mathrm{C}$.

b. Dissolution profile of all systems after 3 months in simulated gastric fluid (SGF) without enzyme at $37 \pm 0.5^{\circ} \mathrm{C}$

CITR: crystalline itraconazole; AITR: amorphous itraconazole

The reason behind poor dissolution rate from binary systems lies in the conversion of amorphous state into crystalline one during accelerated stability testing due to plasticizing effect of moisture (Fitzpatrick et al., 2002). Ternary dispersion system showed significantly better drug release profile over binary systems and amorphous form during stability testing period of 3 months. The statistical analysis of DE values revealed a significant improvement in dissolution profile of itraconazole at $15 \mathrm{~min}$ $\left(\mathrm{DE}_{15}\right)(p<0.05)$. In case of ternary system, no significant decrease in dissolution profile was observed during accelerated stability studies. Further no any event of crystallization process was seen over a period of 3 months endorsing excellent stabilization of AITR. The excellent stabilization achieved was attributed to protection of amorphous form from the effect of moisture by ternary component sylysia $^{\circledR} 350$ thus augmenting the antiplasticizing effect of PVP K30. The findings were also strongly supported by DSC and XRPD studies. 


\section{CONCLUSION}

Based upon the present investigation and results it could be concluded that transformation of itraconazole into glassy state by melt quench technique and formulation of its ternary solid dispersion systems using spray drying technique could be one of the approaches for improvement of its dissolution rate. This investigation points to the importance of combined use of antiplastisizer and adsorbent in enhancing aqueous solubility and in stabilizing amorphous form of itraconazole. These results also suggested that among all formulations ternary dispersion system showed significantly better drug release profile over binary systems and amorphous form even after 3 months. Further studies are required to explore the feasibility of ternary solid dispersion system of amorphous itraconazole as an economic and practical substitute to commercial itraconazole formulations.

\section{ACKNOWLEDGEMENTS}

Authors are grateful to Glenmark Pharma, Mumbai, India for providing gift samples of pure drug itraconazole and polymer PVP K30. The authors acknowledge the support of Fuji Sylysia Chemical Ltd., Japan for providing gift samples of sylysia ${ }^{\circledR} 350$. Acknowledgements are due to Shivaji University, Kolhapur, Maharashtra, India for providing DSC and XRPD facilities and to the Principal of Govt. College of Pharmacy, Karad, Maharashtra, India for providing laboratory facilities and consistent support.

\section{Financial support and sponsorship: Nil.}

Conflict of Interests: There are no conflicts of interest.

\section{REFERENCES}

Ambike AA, Mahadik KR, Paradkar A. Stability study of amorphous valdecoxib. Int J Pharm, 2004; 282:151-162.

Brittain H. 1999. Methods for the charactrization of polymorphs and solvates. In: Brittain HG, ed. Polymorphism in pharmaceutical solids. New York: Marcel Dekker 227-278.

Byrn SR, Pfeiffer RR, Stowell JG. 1999. Solid-state chemistry of drugs. West Lafayette: Indiana 259-366.

Craig DQ, Royall PG, Kett VL, Hopton ML. The relevance of the amorphous state to pharmaceutical dosage forms: glassy drugs and freeze dried systems. Int J Pharm, 1999; 179:179-207.

Fitzpatrick S, McCabe JF, Petts CR, Booth SW. Effect of moisture on polyvinylpyrrolidone in accelerated stability testing. Int $\mathrm{J}$ Pharm, 2002; 246:143-151.

Ford JL. The current status of solid dispersions. Pharm Acta Helv, 1986; 61:69-88.

Hancock BC, Zografi G. Characteristics and significance of the amorphous state in pharmaceutical systems. J Pharm Sci, 1997; 86:1-12.

Heykants J, Van PA, Van de Velde V, Van RP, Meuldermans W, Lavrijsen K, et. al. The clinical pharmacokinetics of itraconazole: an overview. Mycoses, 1989; 32:67-87.

Jondhale S, Bhise SB, Pore YV. Physicochemical investigations and stability studies of amorphous gliclazide. AAPS PharmSciTech, 2012; $13: 448-459$.
Jung JY, Yoo SD, Lee SH, Kim KH, Yoon DS, Lee KH. Enhanced solubility and dissolution rate of itraconazole by a solid dispersion technique. Int J Pharm, 1999; 187:209-218.

Kumar RH, Bandari S, Jukanti R, Veerareddy PR. Solubility enhancement and physicochemical characterization of carvedilol solid dispersion with gelucire 50/13. Arch Pharmacal Res, 2011; 34:51-57.

Lewis RE. Current Concepts in Antifungal Pharmacology. Mayo Clin Proc, 2011; 86:805-817.

Lian Y. Amorphous pharmaceutical solids: preparation, characterization and stabilization. Adv Drug Deliv Rev, 2001; 48:27-42.

Llinas A, Goodman JM. Polymorph control: past, present and future. Drug Discov Today, 2008; 13:198-210.

Mulye SP, Jamadar SA, Karekar PS, Pore YV, Dhawale SC. Improvement in physicochemical properties of ezetimibe using a crystal engineering technique. Powder Technol, 2012; 222:131-138.

Nair R, Gonen S, Hoag AW. Influence of polyethylene glycol and povidone on the polymorphic transformation and solubility of carbamazepine. Int J Pharm, 2002; 240:11-22.

Paul EL, Tung HH, Milder M. Organic crystallization processes. Powder Technol, 2011; 150:133-143.

Pokharkar VB, Mandpe LP, Padamwar MN, Ambike AA Mahadik KR, Paradkar A. Development, characterization and stabilization of amorphous form of a low Tg drug. Powder Technol, 2006; 167:20-25.

Saleki-Gerhardt A, Zografi G. Non-isothermal and isothermal crystallization of sucrose from the amorphous state. Pharm Res, 1994; 11:1166-1173.

Sammour OA, Hammad MA, Megrab NA, Zidan AS. Formulation and optimization of mouth dissolve tablets containing rofecoxib solid dispersion. AAPS PharmSciTech, 2006; 7:E167-175.

Shamblin SL, Huang EY, Zografi G. The effects of colyophilized polymeric additives on the glass transition temperature and crystallization of amorphous sucrose. J Therm Anal, 1996; 47:1567-1579.

Shete A, Murthy S, Korpale S, Yadav A, Sajane S, Sakhare S, Doijad R. Cocrystals of itraconazole with amino acids: Screening, synthesis, solid state characterization, in vitro drug release and antifungal activity. J Drug Deliv Sci and Tech, 2015; 28:46-55.

Tao T, Zhao Y, Wu J, Zhou B. Preparation and evaluation of itraconazole dihydrochloride for the solubility and dissolution rate enhancement. Int J Pharm, 2009; 367:109-114.

Verreck G, Six K, Mooter GV, Baert L, Peeters J, Brewster ME. Characterization of solid dispersions of itraconazole and hydroxypropylmethylcellulose prepared by melt extrusion - part I. Int J Parm, 2003; 251:165-174.

Wang X, Michoel A, Mooter GV. Solid state characteristics of ternary solid dispersions composed of PVP VA64, myrj 52 and itraconazole. Int J Pharm, 2005; 303:54-61.

Yadav AV, Shete AS, Dabke AP, Kulkarni PV, Sakhare SS. Co-crystals: a novel approach to modify physicochemical properties of active ingredients. Ind J Pharm Sci, 2009; 71:359-370.

\section{How to cite this article:}

Pore YV, Shinde VR, Rao JV. Physical stabilization of amorphous itraconazole in solid dispersions for improved dissolution profile. $\mathrm{J}$ App Pharm Sci, 2016; 6 (10): 037-044. 